\title{
Landscape Design and Urban Biodiversity
}

\author{
Norbert Müller $^{1} \cdot$ Yukihiro Morimoto $^{2}$
}

Published online: 10 February 2016

(C) International Consortium of Landscape and Ecological Engineering and Springer Japan 2016

We dedicate this special feature to the forerunners of urban vegetation science: Wolfram Kunick (Bornheim, Germany) and Herbert Sukopp (Berlin, Germany).

\section{Foreword}

The loss of biodiversity, the impact of climate change, and the growth of the world's urban population, the main challenges of this century for life on earth, are all strongly interconnected. The Tenth Conference of the Parties of the Convention on Biological Diversity in Nagoya (Japan) in October 2010 acknowledged that cities can significantly contribute to global efforts to protect and enhance biodiversity and ecosystem services by the adoption of the "Plan of Action on Cities and Biodiversity 2011-2020". This significant political milestone was prepared at two important side-events to COP 10 in Japan, the Second Conference of the International Network for URBIO (URban BIOdiversity \& Design) in May 2010 and ICLEI's City Biodiversity Summit held during the high-level segment of the Tenth Conference of the Parties in October 2010.

This issue will bring out some further contributions held during the Second URBIO Conference in Nagoya in a

Norbert Müller

n.mueller@fh-erfurt.de

Yukihiro Morimoto

morimoto@kyogakuen.ac.jp

1 Department Landscape Management \& Restoration Ecology, University of Applied Sciences Erfurt, Erfurt, Germany

2 Faculty of Bioenvironmental Science, Department of Bioenvironmental Design, Kyoto Gakuen University, Kyoto, Japan follow-up of the Special issue "Biodiversity and Ecosystem Services: Importance of Cities for post 2010 perspective".

We have collected papers from Asia, Europe, South Africa, and South America that examine biodiversity in urban areas and explore how landscape design can influence native biodiversity. The recently published Cities and Biodiversity Outlook has underlined the importance of sustainable landscape design especially for areas including India, China, and South America where rapid global urbanization is predicted for the next three decades.

We are grateful to our Japanese colleagues who organized the URBIO Conference in Nagoya 2010 and to the Journal "Landscape and Ecological Engineering" for publishing further scientific papers from this meeting.

Norbert Müller (URBIO President 2008 - 2014) and Yukihiro Morimoto (URBIO Co-Organizer 2010)

\section{Papers of the Special Issue}

1) Identifying indicator species for bryophyte conservation in fragmented forests

Yoshitaka Oishi \& Yukihiro Morimoto

2) Estimation of leaf area index and gap fraction in two broad-leaved forests by using small-footprint airborne LiDAR

Takeshi Sasaki, Junichi Imanishi, Keiko Ioki, Youngkeun Song \& Yukihiro Morimoto

3) Influence of socioeconomic status on design of Batswana home gardens and associated plant diversity patterns in northern South Africa

Elandrie Davoren, Stefan Siebert, Sarel Cilliers \& Marié Joey du Toit 
4) A multifunctional green infrastructure design to protect and improve native biodiversity in Rio de Janeiro

Cecilia Polacow Herzog
5) Influence of different landscape design styles on plant invasions in Central Europe

Norbert Müller \& Herbert Sukopp. 